\title{
The Long Road to Wearable Blood-Cleansing Devices
}

\author{
Jeroen P. Kooman Frank M. van der Sande Karel M.L. Leunissen \\ Department of Internal Medicine, Division of Nephrology, University Hospital Maastricht, Maastricht, \\ The Netherlands
}

The commonly used dialysis techniques suffer from various drawbacks which preclude the leading of a normal life in patients with end-stage renal failure. Both hemodialysis and peritoneal dialysis are vastly inferior to renal transplantation in terms of correction of the interior milieu, due to the discontinuous nature of hemodialysis and the small efficacy in terms of solute clearance of peritoneal dialysis. This is reflected by the fact that the adjusted mortality for patients with a functioning renal transplant is $40-60 \%$ lower as compared to dialysis patients on the transplant waiting list [1]. In terms of equivalence of renal clearance, 3 times weekly hemodialysis for 4 hours corresponds roughly to a urea clearance of $13 \mathrm{ml} /$ min [2] whereas current guidelines recommend a minimum peritoneal $\mathrm{Kt} / \mathrm{V}_{\text {urea }}$ of 1.7 (roughly corresponding to a weekly peritoneal creatinine clearance of $45 \mathrm{ml} /$ $\mathrm{min} / 1.73 \mathrm{~m}^{2}$ (i.e. $\pm 4.5 \mathrm{ml} / \mathrm{min}$ )) for peritoneal dialysis [3]. The inefficiency of current dialysis techniques is highlighted by the importance of even small amounts of residual renal clearance in the prognosis of dialysis patients $[4,5]$. Apart from these inherent drawbacks, hemodialysis and peritoneal dialysis are disadvantageous from a psychosocial point of view, because patients are either tied to a device for several hours, or have to perform several daily exchanges. Although quotidian hemodialysis results in an improvement of the quality of life and an improvement of the interior milieu, this option appears to be logistically feasible in only a selected number of dialysis centers, given the small number of patients treated in this way [6]. Automated peritoneal dialysis offers more freedom to the patients, but may be disadvantageous to continuous ambulatory peritoneal dialysis (CAPD) in terms of sodium removal, especially in so-called low transporters [7]. Thus, there is a great need for a more comfortable and effective renal replacement technique, also given the great shortage of donor kidneys. Ideally, such a device would function for $24 \mathrm{~h}$ daily, corresponding to the normal functioning of the human kidney, and would be comfortable to wear for the patient. The ultimate dream would be a bioengineered implantable kidney, but the ultimate development of such a device is not foreseeable in the near future. In this aspect, it is sobering to realize that the human kidney is constructed of more than 26 different cell types [8], whose interaction was developed in more than 450 million years of evolution, since our ancestors left the iso-osmotic milieu of the Ordovicians seas and went on to conquer first the freshwater environment, followed by the land [9]. Of course, an implantable blood-cleansing device would not have to be a reliable replica of the normal kidney, and recently the group of Humes succeeded in achieving site-directed neovascularization of an implanted hollow-fiber hemofilter device after addition of angiogenic growth factors, resulting in formation of filtrate [10]. However, in the case of an implantable kidney, formidable problems in terms of immune tolerance, vascular access, and biocompatibility, to name only a few, still lie ahead. However, the construction of exterior devices, or developments which

\section{KARGER}

Fax +4161306 1234

E-Mail karger@karger.ch

www.karger.com (c) 2007 S. Karger AG, Basel

0253-5068/07/0254-0377\$23.50/0

Accessible online at:

www.karger.com/bpu
J.P. Kooman

Department of Internal Medicine, Division of Nephrology

University Hospital Maastricht, PO Box 5800

NL-6202 AZ Maastricht (The Netherlands)

E-Mail jkoo@sint.azm.nl 


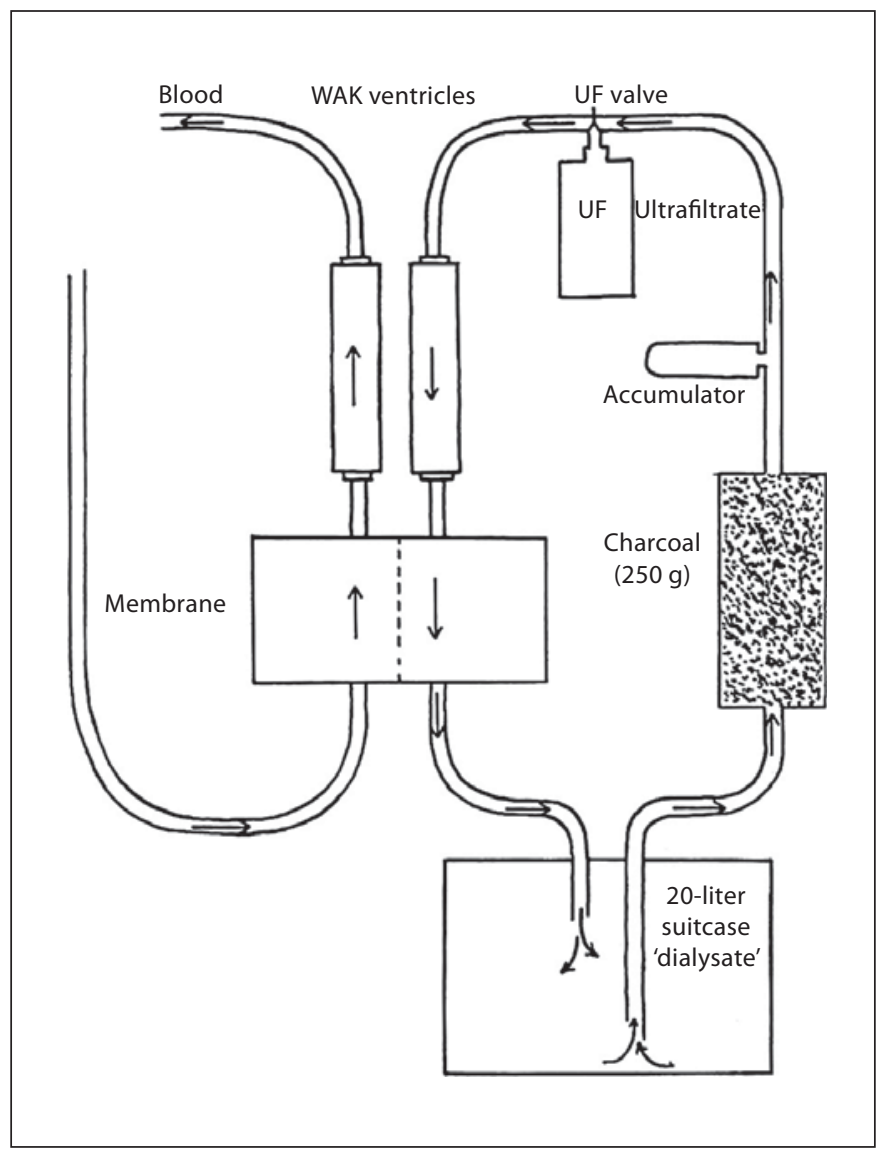

Fig. 1. The first wearable artificial kidney, designed by Kolff et al. The wearable device weighed $3.5 \mathrm{~kg}$, but the patient had to be connected to a 20 -liter dialysis batch during at least $50 \%$ of the dialysis time, because the toxins which had accumulated in the charcoal sorbent had to be equilibrated with the dialysate [reprinted from 11, with permission].

would improve the efficacy of currently used dialysis techniques, appear more feasible in relatively short term. Recently, interest in such devices has been renewed. However, it is important to realize that the first wearable artificial kidney was developed in 1976 by Kolff's group [11], who took many patients on the famous Salmon River trips [12], where they could enjoy a holiday in the wilderness far away from any dialysis center (fig. 1). Also other pioneers have been working on wearable artificial renal replacement devices. A problem is that many wearable devices still remained relatively large and heavy, and thus uncomfortable for a patient to wear on a continuous basis. However, new developments may pave the way for a wider application of wearable devices.

\section{The Wearable Artificial Kidney}

For wearable devices, regeneration of used dialysate or filtrate would be highly desirable. A miniaturized device, called the wearable artificial kidney (WAK), based on the REDY sorbent technology, was developed by Gura et al. [13]. It may be helpful to shortly recapitulate the REDY sorbent technique, which enjoyed some popularity in the early 1980s, but virtually disappeared from clinical practice with the development of mobile reverse osmosis units (fig. 2). With the REDY sorbent device, only 6 liters of dialysate are necessary, which are regenerated by means of an elaborate five-layer reabsorption cartridge, respectively consisting of charcoal, urease, a zirconium phosphate and acetated zirconium oxide, and activated carbon [14]. The WAK, which applies a $0.2 \mathrm{~m}^{2}$ membrane in combination with $375 \mathrm{ml}$ of dialysate, has shown impressive preliminary results. In a study in pigs, a creatinine clearance of $25 \mathrm{ml} / \mathrm{min}$ was reached during an operating time of $8 \mathrm{~h}$. However, although these preliminary results look very promising, there may still be some problems ahead with the use of the WAK for routine clinical practice. Firstly, in the present device, continuous anticoagulation by means of a heparin pump is applied, whereas fine regulation of electrolyte and acid-base balance depends on infusion of calcium, sodium bicarbonate and magnesium from a reservoir. In order to prevent dangerous derangements in electrolyte and acid-base balance, frequent monitoring and adjustment would appear necessary. Also, with a weight of $2.3 \mathrm{~kg}$, the device appears still relatively heavy to wear on a continuous basis. Moreover, although the REDY sorbent technique appeared to be generally safe, earlier experience noted some problems with regard to achieving optimal acid-base balance, and ammonia accumulation due to a misbalance between ammonium production in the urea layer and reabsorption in the zirconium phosphate layer [15]. Still, further clinical trials with the WAK are awaited with great interest.

In relation to the application of absorbent devices, an interesting development is the incorporation of absorbers in polymer membranes (so-called mixed matrix membrane absorbers), which might either be used for a combination of diffusion and absorption in a single dialyzer, or find an application in the regeneration of dialysate or filtrate in a wearable device [16].

\section{The Human Nephron Filter}

In an earlier issue of this journal, Nissenson et al. [17] described the so-called human nephron filter. In this in- 
Fig. 2. The wearable artificial kidney, developed by Gura et al. [13]. The device operates by continuous recirculation of 375 $\mathrm{ml}$ of dialysate through a recirculation system.

Fig. 3. Human nephron filter. Filtrate is formed by the G-membrane. Selective reabsorption follows the G-membrane [17].
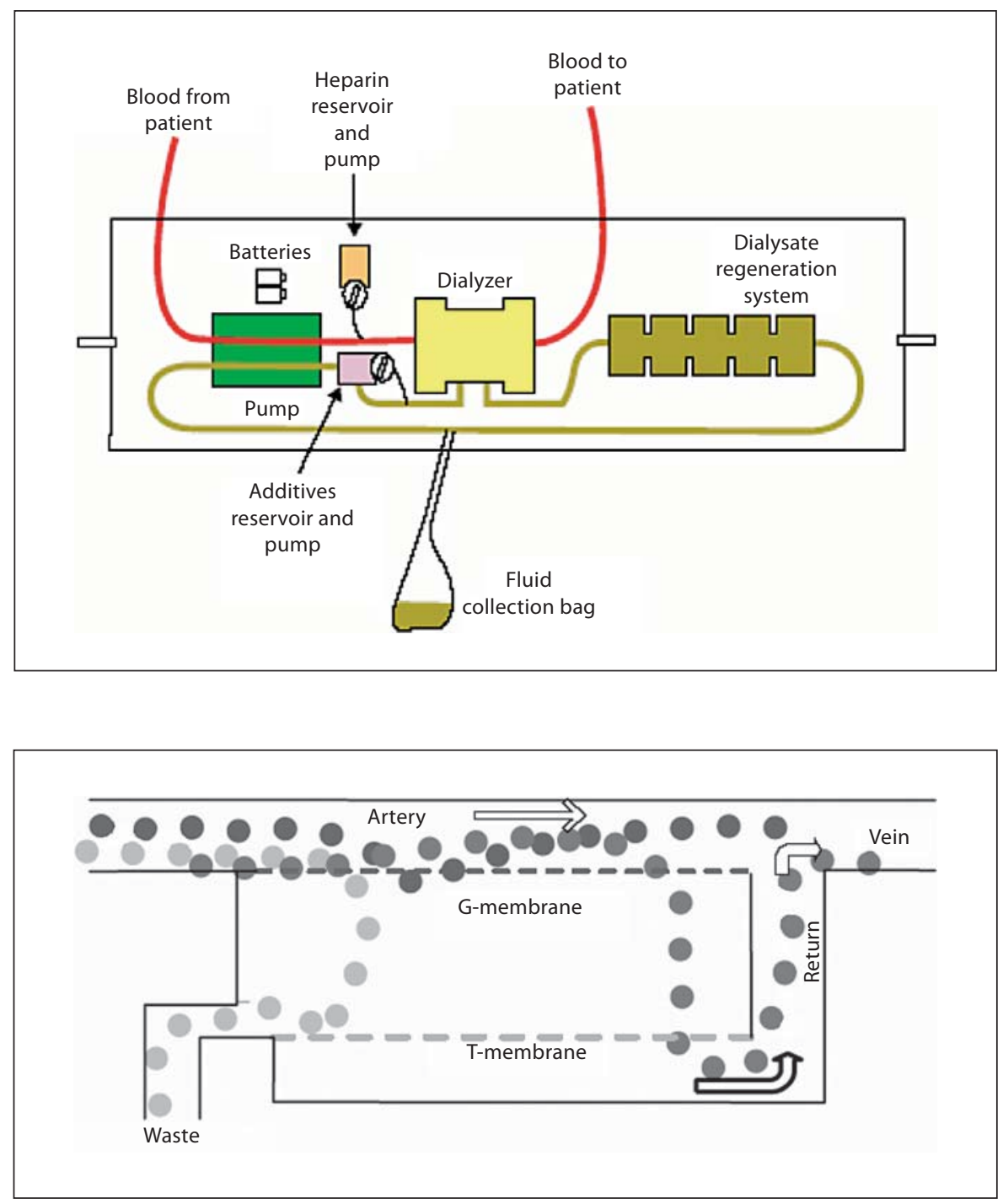

novative idea, a continuously operating artificial kidney is proposed, composed of a glomerular $(\mathrm{G})$ membrane, by which toxins and water were removed, and a (tubular) $\mathrm{T}$ membrane, by which water and electrolytes are reclaimed, also by convective transport (fig. 3). Although this idea is highly appealing, especially the properties of the T-membrane remain somewhat enigmatic, as the mechanisms behind the selective transport through the T-membrane are not described in detail. The properties and pressure gradients of the T-membrane would be critical for achieving an adequate and precise water and electrolyte balance $[18,19]$. Another unresolved issue is the correction of acidosis by the proposed device.

The Long Road to Wearable Blood-Cleansing Devices

\section{Incorporation of Cellular Function:}

The Renal Assist Device

Although not necessarily related to a wearable device, it would appear highly desirable to incorporate cellular functions in combination with a diffusive or filtration technique. Such an approach is already ready for clinical practice and has completed phase 2 trials in patients with acute renal failure, with promising results, such as a reduction in cytokine levels $[19,20]$. In short, in the socalled renal assist device a conventional hemodialyzer is combined with a hollow-fiber cartridge containing $0.5-$ $1.0 \times 10^{9}$ human tubular cells, which are derived from donor organs unsuitable for human transplantation. The rationale behind the use of this device in acute renal fail- 
ure is the addition of immunomodulating and metabolic functions of the tubular cells to conventional renal replacement therapy. At present, such a device is far too large to be considered for a wearable device. However, in the future, it might be possible to combine a wearable technological device with a cartridge containing cultured human epithelial cells. In itself, the use of a bioreactor based on hollow fibers carries the large advantage of preventing the development of an immune response against the donor cells, as direct contact between the patient's blood and the donor cells is prevented. However, longterm cell adhesion to a polymeric membrane may pose some problems. Interestingly, membrane properties beneficial for cell adhesion appeared to be associated with lesser biocompatibility of the membrane. Recently, a bioreactor with outer and an inner polyacrylonitrile hollow fibers, differing in the content of the hydrophilic compound $N$-vinylpyrrolidone, was developed. The biocompatible outer hollow fibers serve for the blood membrane contact, whereas the inner hollow-fiber layer, which is less biocompatible, has improved properties for cell adhesion [21].

\section{New Developments in Membrane Technology}

For a continuous functioning wearable device, the ideal membrane would combine small surface areas with maximal solute clearance and biocompatibility. In this aspect, it is important to realize that new developments in membrane technology are under way, which may evoke a revolution in dialysis technique. The newest development for commercially available dialysis hollow-fiber membranes appears to the construction of a new class of polysulfone membranes by nanospinning, which results in a very narrow distribution of relative pore sizes, facilitating the clearance of large uremic toxins with an albumin loss $<1 \mathrm{~g} /$ treatment [22]. However, this membrane still has a conventional thickness in the micrometer range, which forms a barrier to diffusive solute clearance. This is not a problem for conventional hemodialysis, with its combination of large membrane surface areas and high blood flows. However, when the membrane size has to be greatly diminished, as would be the case for wearable devices, a reduction in membrane thickness would aid in improving solute removal. In this aspect, the recent report regarding a new membrane, synthesized by means of thermal annealing, which combines minimal membrane thickness $(10 \mathrm{~nm}$, i.e. 1,000-fold thinner than conventional dialysis membranes!) with very high pressure tolerance (up to $1 \mathrm{~atm}$ ) is very exciting $[23,24]$. Of importance, this membrane is constructed from silicium, which is in itself a bioincompatible compound [25]. However, recent reports showed successful growth of endothelial cells on poly(dimethyl)siloxane polymers, which improves hope for better biocompatibility [26]. Also, the differentiated growth of renal tubular cells on nanostructured silicon and silicon-related membranes, as shown by Fissel et al., is encouraging in this aspect [33]. With regard to thrombogenic properties of current membranes, the developments of new polymers such as methacryloyloxyethyl phosphorylcholine, which mimic the cells' phospholipid layer, hold promise for an extended filter life of wearable extracorporeal devices [27].

\section{Continuous-Flow Peritoneal Dialysis}

A big advantage of peritoneal dialysis is the continuous nature of the therapy. However, a major drawback is the relatively low efficiency in terms of solute clearance. Although the relative importance of peritoneal solute clearance has been questioned, mainly based on the results of the ADEMEX trial [28], it should be noted that the difference in weekly creatinine clearance between the control and the intervention group was approximately 15 liters/week $/ 1.73 \mathrm{~m}^{2}(1.5 \mathrm{ml} / \mathrm{min})$. Although far from being proven, it is the authors' opinion that it might be highly advantageous for the patient if peritoneal clearances could be increased by a really significant amount. With continuous-flow peritoneal dialysis, for which either two catheters or a split catheter would be needed, peritoneal urea clearances of $20-35 \mathrm{ml} / \mathrm{min}$ have been achieved [29]. However, for routine patient care, conventional continuous-flow peritoneal dialysis is unpractical due to the high fluid volumes needed for this therapy. In this issue, Ronco et al. [30] present the concept of a wearable device for continuous peritoneal dialysis, based on regeneration of used peritoneal dialysate through activated carbons and polystyrenic and ion-exchange resins. The device, for which a double lumen peritoneal catheter is needed, is worn during the daytime and is alternated with conventional nightly dwells with icodextrin. Although the device is still in a developmental stage and has not been tested in a clinical situation, technically weekly peritoneal clearances of 100-110 liters might be achievable, which would represent an approximate twofold in efficacy above conventional CAPD treatment. Although the principle of sorbent regeneration has been proposed previously for continuous-flow peritoneal dialysis [31], the main innovation in this device is the miniaturized design and the remote control of the device by a palmtop com- 
puter. As the authors themselves indicate, problems regarding the addition of glucose and bicarbonate to the regenerated peritoneal dialysate have not been completely resolved, although it is proposed to add glucose on demand through a wearable reservoir. Although the authors propose the use of the device for the daytime period, it might also be advantageous to apply recirculation of the peritoneal dialysate in combination with automated peritoneal dialysis during nighttimes, which might circumvent some of the problems associated with wearable glucose and bicarbonate containing reservoirs.

\section{Conclusion}

Recent years have shown exciting new developments in the construction of wearable blood-cleansing devices. With regard to peritoneal dialysis, wearable devices based on recirculation of dialysate, such as described in this issue, are exciting and hold promise for the improvement of the peritoneal dialysis technique. However, the maxi- mal achievable clearance is likely still too low to result in an acceptable correction of the interior milieu. Although not based on solid evidence, it would appear rational to strive for technological developments which are able to achieve, on a continuous basis, small solute clearances well above $30 \mathrm{ml} / \mathrm{min}$. This assumption appears to be supported by recent data in renal transplant patients from the ALERT study, which were followed for 5-6 years. In patients with serum creatininelevels $>200 \mu \mathrm{mol} / \mathrm{l}$ (roughly equivalent to a GFR of $33 \mathrm{ml} / \mathrm{min} / 1.73 \mathrm{~m}^{2}$, all-cause mortality was $35 \%$ compared to $10 \%$ in patients with serum creatinine levels $<200 \mu \mathrm{mol} / 1$ [32]. For wearable devices based on diffusive or convective principles, especially great efforts have to be placed in biocompatibility, removal of the whole spectrum of uremic toxins, vascular access, and fine regulation of electrolyte and acid-base balance. The first goal would be to achieve a miniaturized, wearable, highly biocompatible device, paving the way for the ultimate challenge of an implantable blood cleansing device.

\section{References}

1 Wolfe RA, Ashby VB, Milford EL, et al: Comparison of mortality in all patients on dialysis, patients on dialysis awaiting transplantation, and recipients of a first cadaveric transplant. N Engl J Med 1999;341:17251730.

2 Tattersall J, Martin-Malo A, Pedrini L, Basci A, Canaud B, Fouque D, Haage P, Konner K, Kooman J, Pizzarelli F, Tordoir J, Vennegoor M, Wanner C, Ter Wee P, Vanholder R: EBPG guideline on dialysis strategies. Nephrol Dial Transplant 2007(suppl 2):ii5ii21.

3 Dombros N, Dratwa M, Feriani M, Gokal R, Heimburger O, Krediet R, Plum J, Rodrigues A, Selgas R, Struijk D, Verger C, EBPG Expert Group on Peritoneal Dialysis: European best practice guidelines for peritoneal dialysis. 7. Adequacy of peritoneal dialysis. Nephrol Dial Transplant 2005(suppl 9): ix24-ix27.

-4 Bargman J, Thorpe K, Churchill D: Relative contribution of residual renal function and peritoneal clearance to adequacy of dialysis: a reanalysis of the CANUSA study. J Am Soc Nephrol 2001;12:2158-2162.
5 Termorshuizen F, Dekker FW, van Manen JG, Korevaar JC, Boeschoten EW, Krediet RT, NECOSAD Study Group: Relative contribution of residual renal function and different measures of adequacy to survival in hemodialysis patients: an analysis of the Netherlands Cooperative Study on the Adequacy of Dialysis (NECOSAD). J Am Soc Nephrol 2004;15:1061-1070.

6 Nesrallah GE, Suri RS, Carter ST, Moist LM, Garg AX, Awaraji C, Lindsay RM: The International Quotidian Dialysis Registry: Annual Report 2007. Hemodial Int 2007;11: 271-277.

7 Rodriguez-Carmona A, Perez-Fontan M, Garca-Naveiro R, Villaverde P, Peteiro J: Compared time profiles of ultrafiltration, sodium removal, and renal function in incident CAPD and automated peritoneal dialysis patients. Am J Kidney Dis 2004;44:132145.

-8 Al-Awqati Q, Oliver JA: Stem cells in the kidney. Kidney Int 2002;61:387-395.

$\checkmark 9$ Vize PD, Smith HW: A homeric view of kidney evolution: a reprint of H.W. Smith's classic essay with a new introduction. Evolution of the kidney. 1943. Anat Rec A Discov Mol Cell Evol Biol 2004;277:344-354.

10 Tiranathanagul K, Dhawan V, Lytle IF, Zhang W, Borschel GH, Buffington DA, Tziampazis E, Brown DL, Humes HD: Tissue engineering of an implantable bioartificial hemofilter. ASAIO J 2007;53:176-186.
-11 Stephens RL, Jacobsen SC, Atkin-Thor E, Kolff W: Portable/wearable artificial kidney (WAK) - initial evaluation. Proc Eur Dial Transplant Assoc 1976;12:511-518.

12 Kolff WJ: Lasker Clinical Medical Research Award. The artificial kidney and its effect on the development of other artificial organs. Nat Med 2002;8:1063-1065.

13 Gura V, Beizai M, Ezon C, Polaschegg HD: Continuous renal replacement therapy for end-stage renal disease. The wearable artificial kidney (WAK). Contrib Nephrol. Basel, Karger, 2005, vol 149, pp 325-333.

14 Blumenkrantz MJ, Gordon A, Roberts M, Lewin AJ, Pecker EA, Moran JK, Coburn JW, Maxwell MH: Applications of the REDY sorbent system to hemodialysis and peritoneal dialysis. Artif Organs 1979;3:230-236.

15 Golper TA. Sorbent hemodialysis. http:// www.uptodate.com

$16 \mathrm{Vu}$ DQ, Koros WJ, Miller SJ: Mixed matrix membranes using carbon molecular sieves. I. Preparation and experimental results. J Memb Sci 2003;211:311-334

17 Nissenson AR, Ronco C, Pergamit G, Edelstein M, Watts R: The human nephron filter: toward a continuously functioning, implantable artificial nephron system. Blood Purif 2005;23:269-274.

18 Fissell WH: Developments towards an artificial kidney. Expert Rev Med Devices 2006; 3:155-165. 
-19 Humes HD, Fissell WH, Tiranathanagul K: The future of hemodialysis membranes. Kidney Int 2006;69:1115-1119.

-20 Humes HD, Weitzel WF, Bartlett RH, Swaniker FC, Paganini EP, Luderer JR, Sobota J: Initial clinical results of the bioartificial kidney containing human cells in ICU patients with acute renal failure. Kidney Int 2004;66: 1578-1588.

-21 Groth T, Seifert B, Albrecht W, Malsch G, Gross U, Fey-Lamprecht F, Michanetzis G, Missirlis Y, Engbers G: Development of polymer membranes with improved haemocompatibility for biohybrid organ technology. Clin Hemorheol Microcirc 2005;32:129143.

22 Ronco C, Bowry SK, Brendolan A, Crepaldi C, Soffiati G, Fortunato A, Bordoni V, Granziero A, Torsello G, La Greca G: Hemodialyzer: from macro-design to membrane nanostructure; the case of the FX class of hemodialyzers. Kidney Int Suppl 2002:126142 .

-23 Striemer CC, Gaborski TR, McGrath JL, Fauchet PM: Charge- and size-based separation of macromolecules using ultrathin silicon membranes. Nature 2007;445:749-753.
24 Van den Berg A, Wessling M: Nanofluidics: silicon for the perfect membrane. Nature 2007;445:726.

25 Fissell WH, Humes HD, Fleishman AJ, Roy S: Dialysis and nanotechnology: now, 10 years, or never? Blood Purif 2007;25:12-17.

26 Shin M, Matsuda K, Ishii O, Terai H, Kaazempur-Mofrad M, Borenstein J, Detmar M, Vacanti JP: Endothelialized networks with a vascular geometry in microfabricated poly(dimethyl siloxane). Biomed Microdevices 2004;6:269-278.

27 Saito A, Aung T, Sekiguchi K, Sato Y: Present status and perspective of the development of a bioartificial kidney for chronic renal failure patients. Ther Apher Dial 2006;10:342347.

28 Paniagua R, Amato D, Vonesh E, CorreaRotter R, Ramos A, Moran J, Mujais S, Mexican Nephrology Collaborative Study Group: Effects of increased peritoneal clearances on mortality rates in peritoneal dialysis: ADEMEX, a prospective, randomized, controlled trial. J Am Soc Nephrol 2002;13:1307-1320.
29 Passlick-Deetjen J, Quellhorst E: Continuous flow peritoneal dialysis: a glimpse into the future. Nephrol Dial Transplant 2001;16: 2296-2299.

>30 Ronco C, Fecondini L: The Vicenza wearable artificial kidney for peritoneal dialysis (ViWAK PD). Blood Purif 2007;25:383-388.

31 Winchester JF, Amerling R, Harbord N, Capponi V, Ronco C: The potential application of sorbents in peritoneal dialysis. Contrib Nephrol. Basel, Karger, 2006, vol 150, pp 336-343.

32 Fellström B, Jardine AG, Soveri I, Cole E, Neumayer HH, Maes B, Gimpelewicz C, Holdaas H, the ALERT Study Group: Renal dysfunction is a strong and independent risk factor for mortality and cardiovascular complications in renal transplantation. Am J Transplant 2005;5:1986-1991.

33 Fissell WH, Manley S, Westover A, Humes HD, Fleischman AJ, Roy S: Differentiated growth of human renal tubule cells on thinfilm and nanostructured materials. ASAIO J 2006;52:221-227. 